\title{
Refractive lens exchange in younger and older presbyopes: comparison of complication rates, 3 months clinical and patient-reported outcomes
}

This article was published in the following Dove Press journal:

Clinical Ophthalmology

28 August 2017

Number of times this article has been viewed

\section{Steven C Schallhorn ${ }^{1-3}$ \\ Julie M Schallhorn' \\ Martina Pelouskova ${ }^{3}$ \\ Jan A Venter ${ }^{3}$ \\ Keith A Hettinger ${ }^{3}$ \\ Stephen J Hannan ${ }^{3}$ \\ David Teenan ${ }^{3}$}

'Department of Ophthalmology, University of California, San Francisco,

CA, USA; ${ }^{2}$ Roski Eye Institute, University of Southern California, Los Angeles, CA, USA; ${ }^{3}$ Optical

Express, Glasgow UK
Correspondence: Steven C Schallhorn I 730 Caminito Prenticia, San Diego, CA 92131 , USA

Email scschallhorn@yahoo.com
Purpose: To compare refractive and visual outcomes, patient satisfaction, and complication rates among different age categories of patients who underwent refractive lens exchange (RLE).

Methods: A stratified, simple random sample of patients matched on preoperative sphere and cylinder was selected for four age categories: 45-49 years (group A), 50-54 years (group B), 55-59 years (group C), and 60-65 years (group D). Each group contained 320 patients. All patients underwent RLE with a multifocal intraocular lens at least in one eye. Three months postoperative refractive/visual and patient-reported outcomes are presented.

Results: The percentage of patients that achieved binocular uncorrected distance visual acuity 20/20 or better was $91.6 \%$ (group A), $93.8 \%$ (group B), 91.6\% (group C), 88.8\% (group D), $P=0.16$. Binocularly, $80.0 \%$ of patients in group $A, 84.7 \%$ in group $\mathrm{B}, 78.9 \%$ in group $\mathrm{C}$, and $77.8 \%$ in group D achieved $20 / 30$ or better uncorrected near visual acuity $(P=0.13)$. The proportion of eyes within $0.50 \mathrm{D}$ of emmetropia was $84.4 \%$ in group A, $86.8 \%$ in group B, $85.7 \%$ in group $\mathrm{C}$, and $85.8 \%$ in group $\mathrm{D}(P=0.67)$. There was no statistically significant difference in postoperative satisfaction, visual phenomena, dry eye symptoms, distance or near vision activities. Apart from higher rate of iritis in the age group 50-55 years, there was no statistically significant difference in postoperative complication rates.

Conclusion: RLE can be safely performed in younger as well as older presbyopes. No significant difference was found in clinical or patient-reported outcomes.

Keywords: refractive lens exchange, multifocal IOLs, younger/older presbyopes

\section{Introduction}

Refractive lens exchange (RLE) is a popular surgical modality among presbyopes, and it is no longer restricted to only patients with prescriptions outside of limits of keratorefractive surgery. ${ }^{1-4}$ Intraocular lens (IOL) designs have advanced tremendously over the past 3 decades, ${ }^{1,2}$ and more and more patients in presbyopic age range, regardless of the amount of preoperative refractive error, seek simultaneous correction of distance, intermediate, and near vision.

RLE is often the best surgical option for older presbyopes, as it focuses on the main reason for presbyopia development (aging crystalline lens) and prevents formation of the cataract in the future. ${ }^{3,4}$ Some surgeons are, however, cautious about performing RLE on younger presbyopes owing to the associated optical side effects and surgical risks. In theory, younger presbyopic patients are more active and might have higher visual demands. Some optical side effects associated with multifocal IOLs, such as glare, halo, loss of contrast sensitivity, ${ }^{1,2}$ might therefore be more bothersome in this group of patients. RLE is also associated with rare but vision-threatening complications, 
such as persistent macular edema, ${ }^{4}$ endopthalmitis ${ }^{5}$ or retinal detachment (RD). ${ }^{6-11}$ Particularly, RD is one of the main concerns in younger myopic patients with longer axial lengths, ${ }^{6-11}$ who have not yet undergone a complete posterior vitreous detachment.

As these are valid concerns that deserve investigation, we have undertaken a review of younger presbyopic patients undergoing RLE in comparison to older patients. In this study, we compared visual and refractive outcomes, complication rates, and patient-reported satisfaction among four different age categories, ranging between 45 and 65 years.

\section{Patients and methods}

This retrospective study was deemed exempt from full review by the Committee of Human Research at the University of California, San Francisco, because it used only retrospective, de-identified patient data. Informed consent to undergo RLE and to use de-identified treatment data for research purposes and statistical analysis was obtained from all patients.

Outcomes of patients in four age categories (group A: 45-49 years, group B: 50-54 years, group C: 55-59 years and group D: 60-65 years) who underwent RLE with an implantation of a multifocal lens at least in one eye (Lentis Mplus, Oculentis $\mathrm{GmbH}$, Berlin, Germany) were compared in this study. For each age category, a stratified, simple random sample of 320 patients, designed to reduce selection bias, was extracted from the electronic database of Optical Express (Glasgow, UK), a large European provider of refractive surgery. All four samples were matched on preoperative sphere and cylinder. The following data extraction criteria were used: preoperative corrected distance visual acuity (CDVA) 20/20 or better in each eye; preoperative ametropia with patient dependent on both distance and near correction; attendance of the 3 months clinical examination and completion of a postoperative patient experience questionnaire. Exclusion criteria were a history of glaucoma or RD, corneal disease, previous ocular surgery, ocular inflammation, neuro-ophthalmic disease, macular degeneration or retinopathy. Patients younger than 50 years with axial length over $26 \mathrm{~mm}$ were preoperatively referred to a vitreoretinal specialist for a complete retinal exam to exclude the presence of retinal pathology that would increase the risk of a RD. All patients underwent the procedure for refractive reasons and did not have cataract.

Preoperative examination included detailed ophthalmic examination with manifest and cycloplegic refraction, uncorrected distance visual acuity (UDVA), CDVA, uncorrected near visual acuity (UNVA), slit-lamp evaluation, dilated fundoscopy, autorefraction and tonometry (Tonoref II; Nidek Co. Ltd., Gamagori, Japan), corneal topography (Pentacam;
Oculus, Inc., Wetzlar, Germany), endothelial cell count (SP 2000P specular microscope; Topcon Europe BV, Capelle aan den Ijssel, the Netherlands), biometry (IOLMaster; Carl Zeiss Meditec AG, Jena, Germany) and retinal optical coherence tomography (Cirrus 4000 OCT; Carl Zeiss Meditec $A G)$. In patients who were found to be candidates for either laser vision correction or an RLE procedure, it was their preference that determined the procedure type. Patient preference for RLE was primarily driven by their desire to have a procedure which would eliminate a future cataract.

Visual acuity was measured at distance with a Snellen visual acuity chart and at $40 \mathrm{~cm}$ (near) with a logarithmic near visual acuity chart (Early Treatment Diabetic Retinopathy Study). Near visual acuity was recorded in Snellen distance equivalent (meters). The Haigis or Holladay II formula was used for most of the lens calculation and all eyes were targeted for emmetropia.

Postoperatively, patients were evaluated at 1 day, 1 week, 1 month, and 3 months by a qualified optometrist. At each visit, refraction, CDVA, UDVA, and UNVA were measured. At follow-up visits, patients were required to complete a purpose-developed satisfaction questionnaire (Table S1). It was self-administered by the patient using a password-protected and secure computer terminal in an isolated area of the clinic. The questionnaire responses were stored in the secured central database, which is compliant with ISO 27001 for information security management systems. All response fields used a Likert scale to obtain the patient's preferences or degree of agreement. A 3 months postoperative questionnaire was completed in all patients and used for analysis. In some patients, we were able to retrieve a preoperative questionnaire and calculate the change in visual phenomena symptoms, or difficulties performing tasks requiring close-up and distance vision. Although the number of patients with both pre- and postoperative questionnaires was only approximately 50\% in each category (Table S2), we include this analysis for illustrative purpose.

Three months postoperative data are presented for refractive/visual outcomes, whereas complication rates were calculated from all available exams.

\section{IOLs}

All patients had the Lentis Mplus IOL with 3.0 D near addition implanted at least in one eye. In eyes with corneal astigmatism less than 1.50 D, non-toric IOL (Lentis Mplus LS-313 MF30; Oculentis GmbH) was used and a toric IOL was implanted in eyes with corneal astigmatism 1.50 D or more (model Lentis Mplus Toric LU-313 MF30T; Oculentis $\mathrm{GmbH})$. All patients had their non-dominant eye treated first and a lens with $3.0 \mathrm{D}$ near addition was implanted in all 
Table I IOL types in first and second eyes

\begin{tabular}{|c|c|c|c|c|}
\hline & $45-49$ years & $50-54$ years & 55-59 years & 60-64 years \\
\hline \multicolumn{5}{|l|}{$\begin{array}{l}\text { IOL in first eye: Lentis Mplus with } 3.0 \mathrm{D} \text { near add in all cases } \\
\text { (model LS-313 MF30 [non-toric] or LU-3/3 MF30T [toric]) }\end{array}$} \\
\hline \multicolumn{5}{|l|}{ IOL in second eye: (number of eyes [\%]) } \\
\hline $\begin{array}{l}\text { Lentis Mplus with } 3.0 \text { D near add } \\
\text { (model LS-3/3 MF30 [non-toric] or LU-3/3 MF30T [toric]) }\end{array}$ & 250 (78.1\%) & 248 (77.5\%) & 235 (73.4\%) & $25 \mathrm{I}(78.4 \%)$ \\
\hline $\begin{array}{l}\text { Lentis MplusX with } 3.0 \text { D near add } \\
\text { (model LS-3/3 MF30 [non-toric] or LU-3|3 MF30T [toric]) }\end{array}$ & 45 (14.1\%) & 40 (I2.5\%) & $50(15.6 \%)$ & $33(10.3 \%)$ \\
\hline $\begin{array}{l}\text { Lentis Mplus with low near add }(+\mid .5 \text { or }+2.0 \text { D) } \\
\text { (model LS-3I3 MFI5 or LS-3I3 MF20) }\end{array}$ & $13(4.1 \%)$ & $15(4.7 \%)$ & $26(8.1 \%)$ & $24(7.5 \%)$ \\
\hline Other multifocal IOL & $3(0.9 \%)$ & $2(0.6 \%)$ & $4(1.3 \%)$ & $4(1.3 \%)$ \\
\hline Monofocal IOL & $9(2.8 \%)$ & $12(3.8 \%)$ & $3(0.9 \%)$ & $8(2.5 \%)$ \\
\hline $\begin{array}{l}\text { Did not proceed with second eye } \\
\text { (not an intention) }\end{array}$ & $0(0 \%)$ & I (0.3\%) & $2(0.6 \%)$ & $0(0 \%)$ \\
\hline $\begin{array}{l}\text { Did not proceed with second eye } \\
\text { (unhappy with first eye) }\end{array}$ & $0(0 \%)$ & $2(0.6 \%)$ & $0(0 \%)$ & $0(0 \%)$ \\
\hline
\end{tabular}

Abbreviation: IOL, intraocular lens.

cases. Following the first eye surgery, patients' symptoms were evaluated and a decision was made regarding which lens would be the most appropriate for their dominant eye. If a patient had no significant issues, an IOL with the same reading strength was implanted in their dominant eye. Patients with intermediate vision issues or moderate visual phenomena usually proceeded with a low near addition IOL $(1.50 \mathrm{D})$ in their second eye. Some patients with severe visual phenomena selected a monofocal IOL for their dominant eye, or decided not to proceed with second eye surgery at all.

Table 1 shows IOL types implanted in second eyes of patients in each age category. The majority of patients proceeded with the same IOL in the second eye (Lentis Mplus) or with an IOL of a similar design with the same near addition (Lentis Mplus ${ }^{\mathrm{X}}$ ). A small percentage of patients had an IOL with a lower reading add, different design of multifocal IOL or a monofocal IOL implanted in the second eye, or did not proceed with surgery in the second eye (Table 1).

The Lentis Mplus IOL, used in the majority of eyes in this study, is a refractive, non-rotational symmetric lens with an overall length of $12.0 \mathrm{~mm}$, optic diameter of $6.0 \mathrm{~mm}$, and a plate haptic design. It is composed of a hydrophilic acrylic material with a hydrophobic surface (Benz25 UV). This IOL combines an aspheric distance vision zone with a sector-shaped near vision zone with $+3.00 \mathrm{D}$ add.

\section{Surgical technique}

The procedures were performed at five surgical centers across the UK by 14 experienced surgeons. Incisions were made on the steepest corneal meridian to neutralize corneal astigmatism unless this was impossible due to patient anatomy. After phacoemulsification using the AMO Whitestar Signature platform (Johnson \& Johnson Vision Care, Inc, Santa Ana, CA, USA), the IOL was inserted in the capsular bag using the Viscoject 2.2 injector (Medicel, Wolfhalden, Switzerland). Surgery in the second eye was usually performed 1 week later.

Postoperatively, patients were instructed to instill one drop of levofloxacin $0.5 \%$, four times daily for 2 weeks, one drop of dexamethasone $0.1 \%$, four times daily for 2 weeks, and one drop of ketorolac trometamol $0.5 \%$, four times daily for 1 month.

Patients who did not achieve emmetropia following lens implantation were offered an enhancement procedure (typically laser vision correction) once the refractive stability was achieved, no earlier than 3 months postoperatively. Refractive/visual outcomes presented in this study are prior to any enhancement procedure.

\section{Statistical analysis}

All data were analyzed with Microsoft Office Excel 2007 program (Microsoft Corporation, Redmond, WA, USA) and STATISTICA (Dell StatSoft, Tulsa, OK, USA). One-way analysis of variance (ANOVA) was used to compare all continuous variables between age groups and a chi square test was used to compare proportions. A $P$-value of 0.05 or less was considered statistically significant.

\section{Results}

Four age groups were delineated as follows: $45-49$ years, 50-54 years, 55-59 years, and 60-65 years. There were 320 randomly selected patients in each group who met 
Table 2 Preoperative and postoperative clinical data

\begin{tabular}{|c|c|c|c|c|c|}
\hline Age category & 45-49 years & $50-54$ years & $55-59$ years & 60-65 years & $P$-value \\
\hline Number of patients (eyes) & $320(640)$ & $320(637)$ & $320(638)$ & $320(640)$ & \\
\hline Age & $47.6 \pm 1.3$ & $52.1 \pm 1.4$ & $56.9 \pm 1.5$ & $62.4 \pm 1.7$ & $<0.01$ \\
\hline \multicolumn{6}{|l|}{ Mean \pm SD } \\
\hline Female/male & $60 \% / 40 \%$ & $53.5 \% / 46.5 \%$ & $59.3 \% / 40.7 \%$ & $58.4 \% / 41.6 \%$ & 0.08 \\
\hline \multicolumn{6}{|l|}{ Preoperative data } \\
\hline Sphere & $+1.75 \pm 2.48$ & $+1.73 \pm 2.56$ & $+1.75 \pm 2.56$ & $+1.67 \pm 2.59$ & 0.93 \\
\hline Mean \pm SD (range) [D] & $(-7.75$ to +7.25$)$ & $(-10.5$ to +7.50$)$ & $(-7.25$ to +7.5$)$ & $(-13.5$ to +7.25$)$ & \\
\hline Cylinder & $-0.76 \pm 0.92$ & $-0.69 \pm 0.85$ & $-0.75 \pm 0.76$ & $-0.79 \pm 0.84$ & 0.18 \\
\hline Mean \pm SD (range) [D] & $(-7.00$ to 0.00$)$ & $(-7.50$ to 0.00$)$ & $(-6.00$ to 0.00$)$ & $(-5.50$ to 0.00$)$ & \\
\hline MSE & $+1.37 \pm 2.49$ & $+1.39 \pm 2.61$ & $+1.37 \pm 2.53$ & $+1.27 \pm 2.63$ & 0.85 \\
\hline Mean \pm SD (range) [D] & $(-8.38$ to +6.25$)$ & $(-10.63$ to +7.25$)$ & $(-8.5$ to +7.00$)$ & $(-15.25$ to +6.50$)$ & \\
\hline CDVA & $-0.06 \pm 0.05$ & $-0.06 \pm 0.05$ & $-0.06 \pm 0.04$ & $-0.05 \pm 0.06$ & 0.01 \\
\hline Mean \pm SD (range) [logMAR] & $(-0.18$ to 0.00$)$ & $(-0.18$ to 0.00$)$ & $(-0.18$ to 0.00$)$ & $(-0.18$ to 0.00$)$ & \\
\hline \multicolumn{6}{|l|}{ Postoperative data } \\
\hline Sphere & $+0.12 \pm 0.45$ & $+0.15 \pm 0.4 \mid$ & $+0.16 \pm 0.44$ & $+0.15 \pm 0.43$ & 0.28 \\
\hline Mean \pm SD (range) [D] & $(-2.00$ to +2.75$)$ & $(-2.00$ to +1.25$)$ & $(-1.75$ to +1.75$)$ & $(-2$ to +2.25$)$ & \\
\hline Cylinder & $-0.38 \pm 0.45$ & $-0.36 \pm 0.40$ & $-0.37 \pm 0.42$ & $-0.39 \pm 0.43$ & 0.57 \\
\hline Mean \pm SD (range) [D] & $(-4.25$ to 0.00$)$ & $(-2.25$ to 0.00$)$ & $(-2.25$ to 0.00$)$ & $(-2.25$ to 0.00$)$ & \\
\hline MSE & $-0.07 \pm 0.43$ & $-0.03 \pm 0.41$ & $-0.02 \pm 0.43$ & $-0.05 \pm 0.4$ & 0.11 \\
\hline Mean \pm SD (range) $[D]$ & $(-2.13$ to +1.38$)$ & $(-2.38$ to +1.25$)$ & $(-2.13$ to +1.63$)$ & $(-2.13$ to +1.25$)$ & \\
\hline Monocular UDVA & $0.00 \pm 0.12$ & $-0.01 \pm 0.11$ & $0.00 \pm 0.11$ & $0.01 \pm 0.12$ & 0.10 \\
\hline Mean \pm SD (range) [logMAR] & $(-0.18$ to 0.80$)$ & $(-0.18$ to 0.80$)$ & $(-0.2$ to 0.60$)$ & $(-0.18$ to 0.70$)$ & \\
\hline Binocular UDVA & $-0.05 \pm 0.08$ & $-0.06 \pm 0.07$ & $-0.05 \pm 0.08$ & $-0.05 \pm 0.08$ & 0.09 \\
\hline Mean \pm SD (range) [logMAR] & $(-0.18$ to 0.4$)$ & $(-0.18$ to 0.3$)$ & $(-0.18$ to 0.3$)$ & $(-0.18$ to 0.52$)$ & \\
\hline Monocular UNVA & $0.21 \pm 0.16$ & $0.21 \pm 0.15$ & $0.22 \pm 0.16$ & $0.21 \pm 0.17$ & 0.57 \\
\hline Mean \pm SD (range) [logMAR] & $(-0.3$ to 0.8$)$ & $(-0.08$ to 0.9$)$ & $(-0.08$ to 0.9$)$ & $(-0.3$ to 1.0$)$ & \\
\hline Binocular UNVA & $0.16 \pm 0.13$ & $0.16 \pm 0.12$ & $0.17 \pm 0.13$ & $0.17 \pm 0.14$ & 0.36 \\
\hline Mean \pm SD (range) [logMAR] & $(-0.3$ to 0.7$)$ & $(-0.1$ to 0.8$)$ & $(-0.10$ to 0.78$)$ & $(-0.3$ to 0.76$)$ & \\
\hline Monocular CDVA & $-0.05 \pm 0.06$ & $-0.06 \pm 0.06$ & $-0.05 \pm 0.06$ & $-0.05 \pm 0.07$ & 0.03 \\
\hline Mean \pm SD (range) [logMAR] & $(-0.18$ to 0.3$)$ & $(-0.18$ to 0.4$)$ & $(-0.2$ to 0.4$)$ & $(-0.18$ to 0.4$)$ & \\
\hline
\end{tabular}

Abbreviations: MSE, manifest spherical equivalent; UDVA, uncorrected distance visual acuity, UNVA, uncorrected near visual acuity; CDVA, corrected distance visual acuity.

the selection criteria. The number of eyes in each group ranged from 637-640, depending on whether the patients all had second eye surgery or not. All groups were well matched on preoperative sphere and cylinder. Table 2 shows preoperative and postoperative refractive and visual outcomes of the four age categories. Most of the preoperative variables were comparable between the four groups. Figure 1 presents the distribution of preoperative manifest spherical equivalent (MSE).

\section{Refractive outcomes}

Three months postoperatively, the percentage of patients within 0.50 D of emmetropia was as follows: group A: $84.4 \%$, group B: $86.8 \%$, group C: $85.7 \%$, group D: $85.8 \%(P=0.67)$. The proportion of eyes within $1.0 \mathrm{D}$ of emmetropia was $96.1 \%$ in group A, $97.8 \%$ in group B, $97.3 \%$ in group C, and $97.5 \%$ in group $\mathrm{D}(P=0.27)$. There was no statistically significant difference in the mean postoperative sphere, cylinder or MSE (Table 2). Figure 2 shows refractive outcomes for all age categories.

\section{Uncorrected visual acuity}

Figures 3 and 4 display postoperative distance and near visual acuity. The percentage of eyes that achieved monocular UDVA $20 / 20$ or better was $75.2 \%$ in group $A, 78.2 \%$ in group B, $77.9 \%$ in group $\mathrm{C}$, and $74.8 \%$ in group $\mathrm{D}(P=0.35)$. Similarly, there was no statistically significant difference in patients achieving binocular UDVA 20/20 or better (group A: 91.6\%, group B: $93.7 \%$, group C: $91.6 \%$, group D: $88.8 \%$, $P=0.16)$.

Monocular UNVA 20/30 or better (approximately J3) was achieved in $69.1 \%$ in group A, 68.1\% in group B, $63.9 \%$ in group $\mathrm{C}$, and $70.8 \%$ in group $\mathrm{D}(P=0.06)$. Binocularly, $80.0 \%$ of patients in group A, $84.7 \%$ in group B, $78.8 \%$ in group $C$, and $77.8 \%$ in group D achieved $20 / 30$ or better UNVA $(P=0.13)$. There was no statistically significant difference 


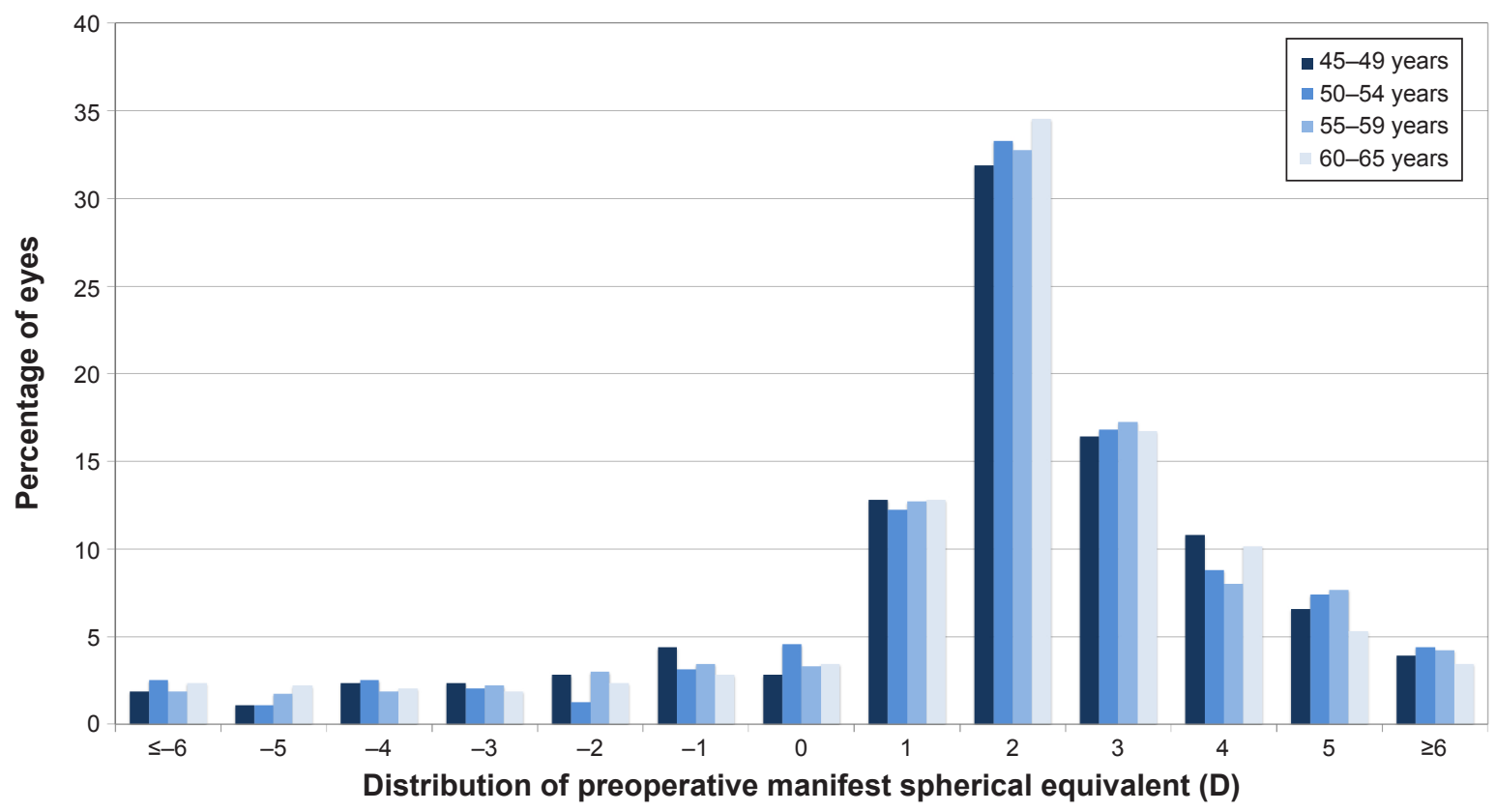

Figure I Distribution of preoperative manifest spherical equivalent.

in the mean postoperative monocular or binocular UDVA or UNVA (Table 2) between the four groups.

\section{Corrected visual acuity}

Figure 5 depicts the change in pre- to postoperative CDVA. Three months postoperatively, $3.1 \%$ of eyes in group A, $2.8 \%$ in group $\mathrm{B}, 1.9 \%$ in group $\mathrm{C}$, and $3.6 \%$ in group $\mathrm{D}(P=0.31)$ had CDVA reduced by two lines or more.
Of all eyes that lost two or more lines of CDVA in group A, only two eyes had CDVA worse than 20/25 (one due to posterior capsular opacification [PCO], one due to poor quality tear film). Seventeen of 20 eyes that lost two or more lines of CDVA at 3 months had 20/20 or better CDVA at the final visit.

Of all eyes that lost two or more lines of CDVA in group B, only one eye had CDVA worse than 20/25 (due to PCO).

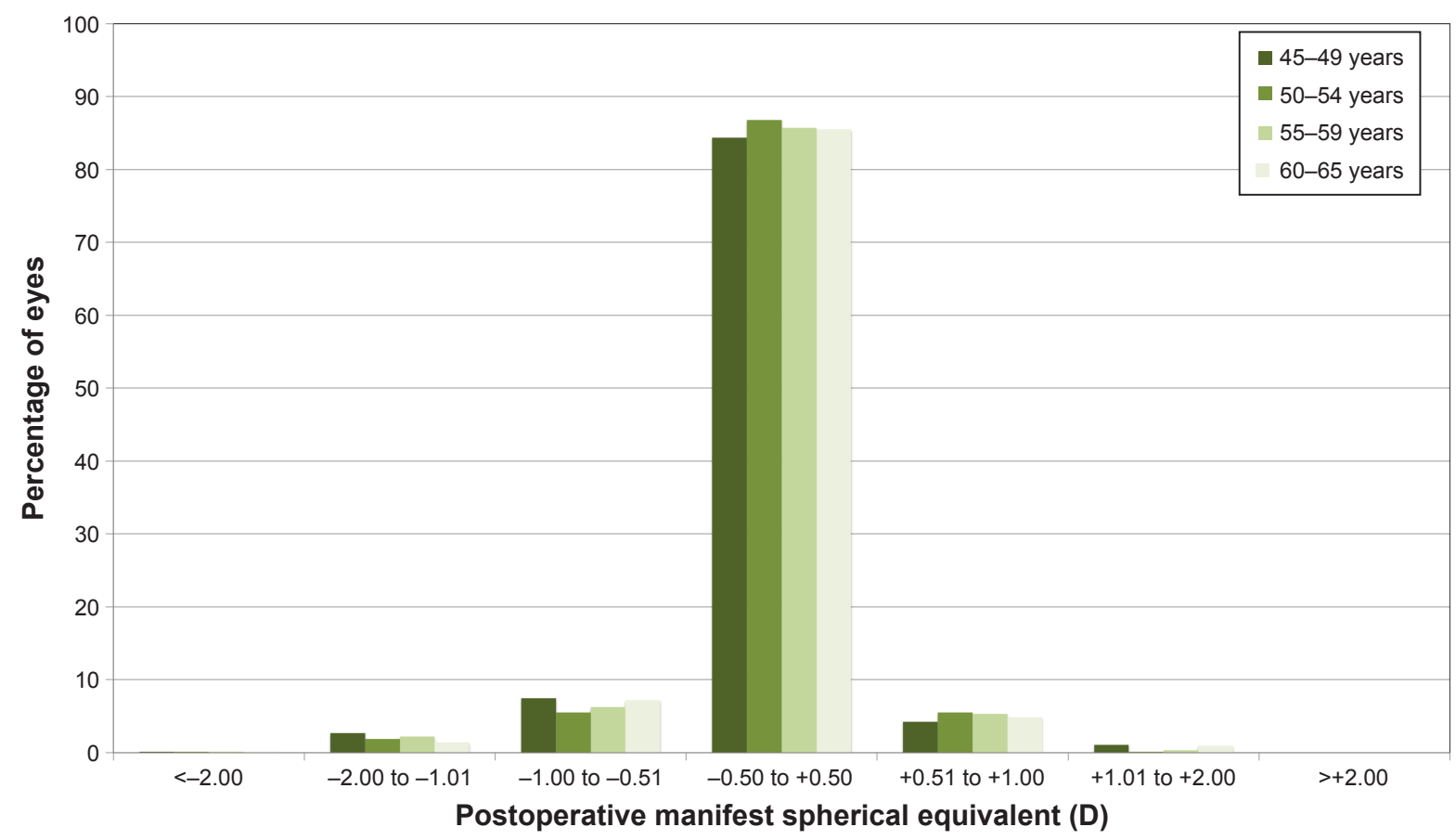

Figure 2 Refractive outcomes: distribution of 3 month postoperative manifest spherical equivalent. 


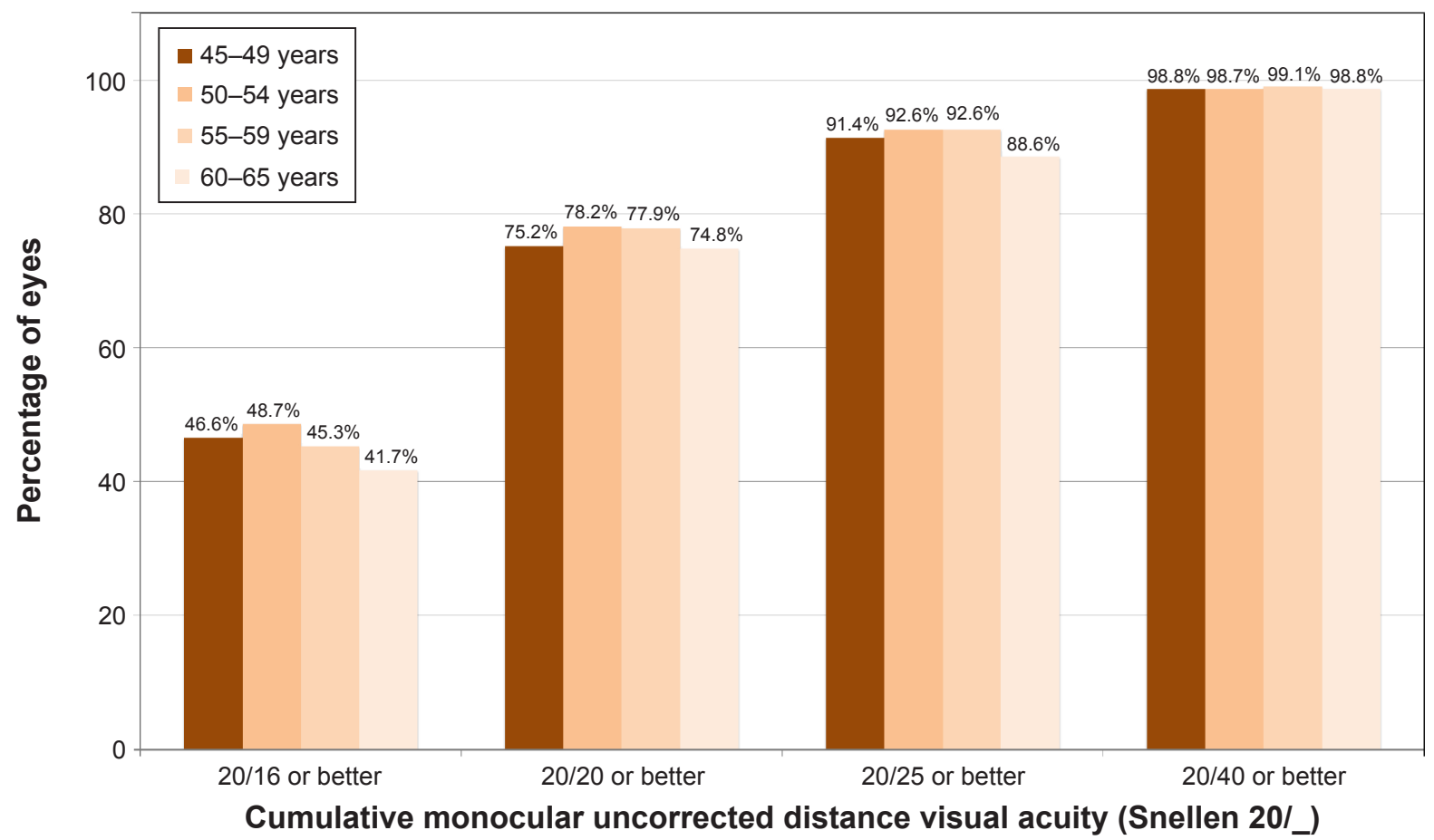

Figure 3 Cumulative monocular uncorrected distance visual acuity. Note: Follow-up 3 months.

Seventeen of 18 eyes that lost two or more lines of CDVA at 3 months had 20/20 or better CDVA at the final visit.

Of all eyes that lost two or more lines of CDVA in group C, six eyes had CDVA worse than 20/25 (four due to PCO, one due to poor quality tear film, and one for unexplained reason).
Nine of 12 eyes that lost two or more lines of CDVA at 3 months had 20/20 or better CDVA at the final visit.

Of all eyes that lost two or more lines of CDVA in group D, three eyes had CDVA worse than 20/25 (one due to PCO, one due to iritis, and one due to corneal Descemet folds).

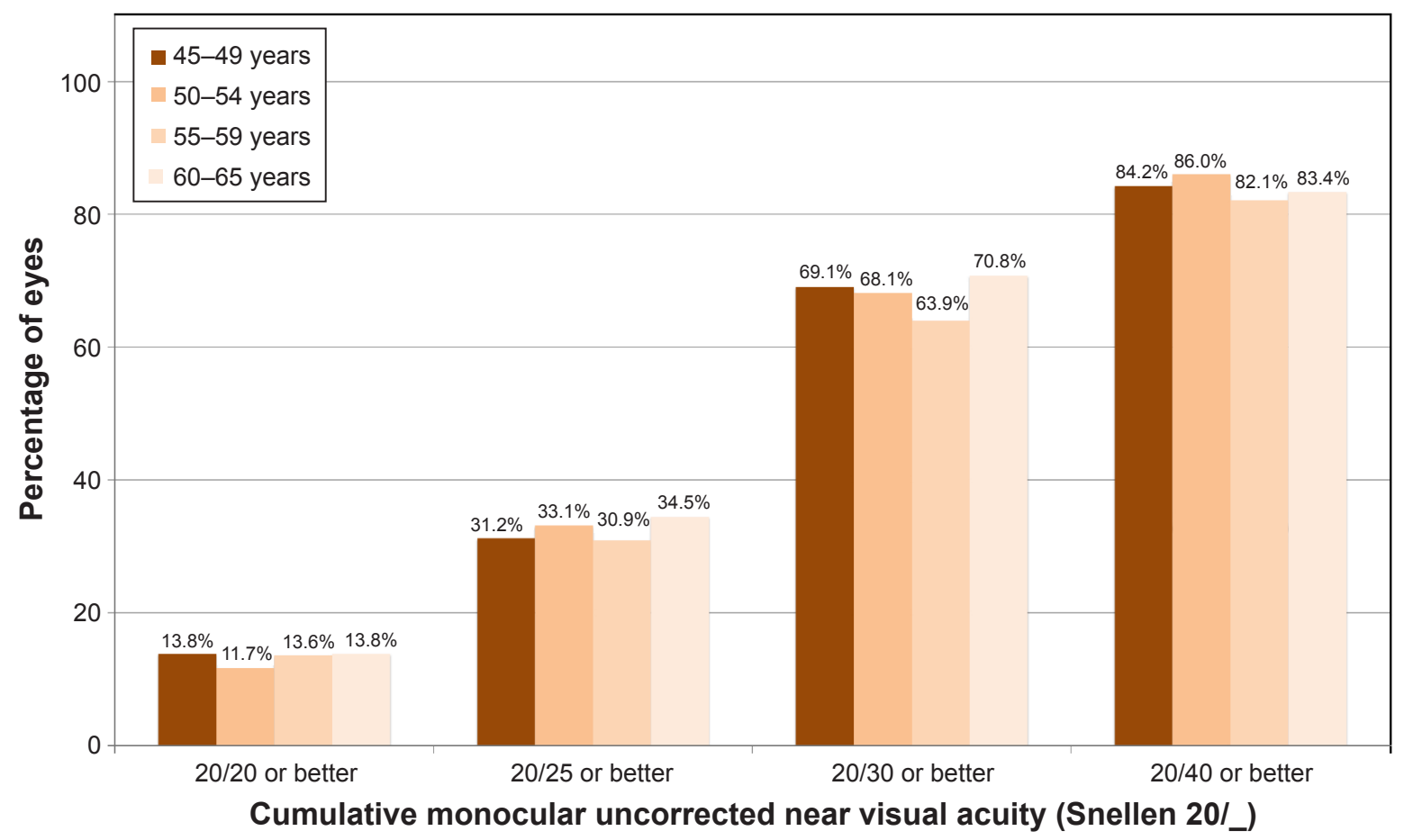

Figure 4 Cumulative monocular uncorrected near visual acuity. Note: Follow-up 3 months. 


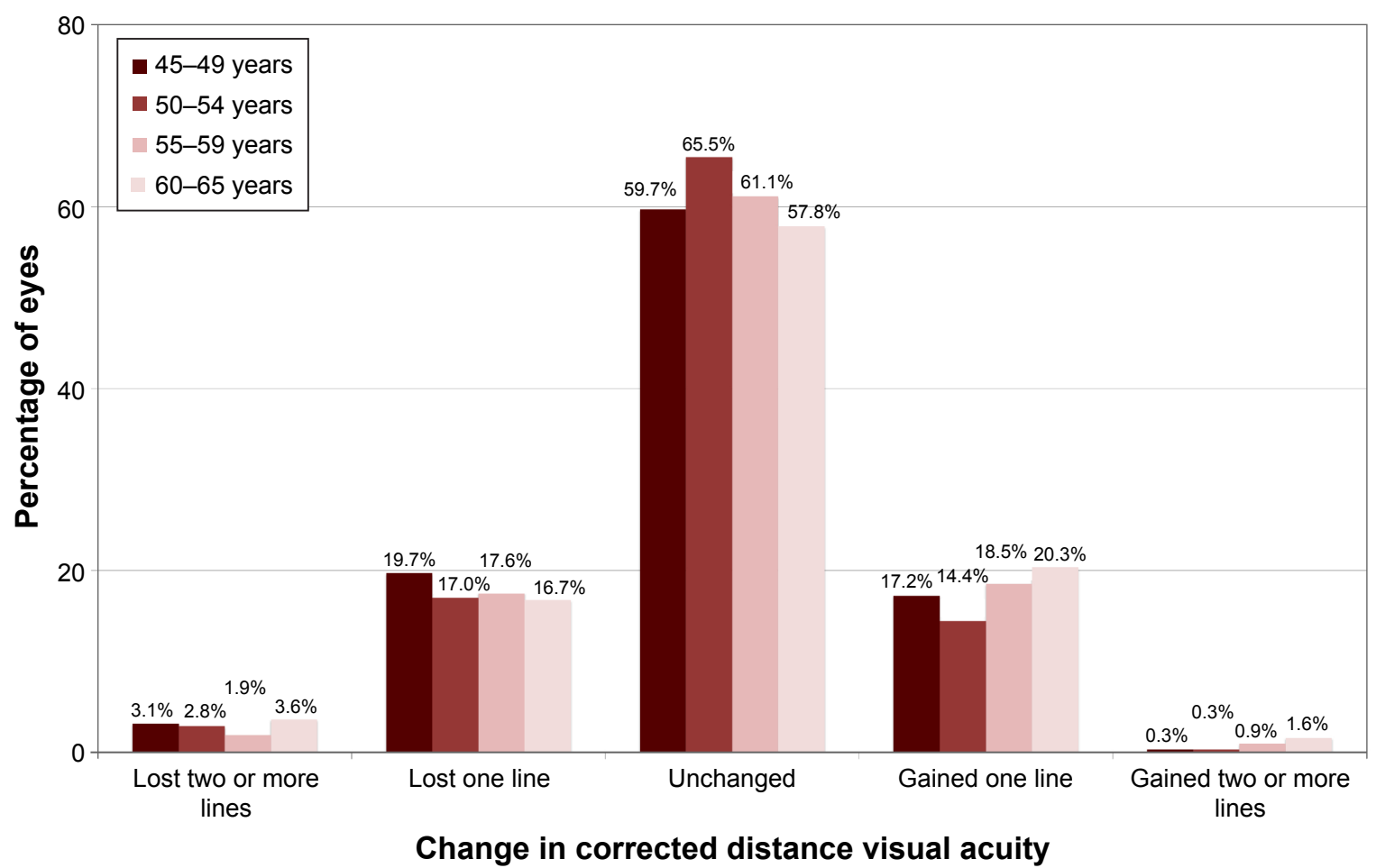

Figure 5 Comparison of preoperative and postoperative corrected distance visual acuity.

Note: Follow-up 3 months.

Twenty-one of 23 eyes that lost two or more lines of CDVA at 3 months had 20/20 or better CDVA at the final visit.

\section{Patient-reported outcomes}

Patient-reported outcomes were tracked with a standardized, confidentially administered questionnaire, as described in the methods section. Table S1 summarizes outcomes for all questionnaire items. General satisfaction with vision was comparable between groups and the percentage of satisfied/ very satisfied patients was close to $90 \%$ in each group.

There was no statistically significant difference in visual phenomena between age groups. In most categories, up to $10 \%$ of patients experienced significant visual phenomena (score of 6 or 7), which is not unexpected in the early postoperative time period, and typically improves over time with neuroadaptation.

No statistically significant difference in dry eye symptoms was found, with only a small percentage of patients ( $1.3 \%$ to $3.8 \%)$ experiencing significant dry eye symptoms at 3 months.

Questions related to the quality of distance vision (night driving, outdoor activities, sport) and near vision also had comparable outcomes between age groups. Between 7.0\% to $11.3 \%$ of patients had significant difficulty with night driving, $1.9 \%$ to $3.4 \%$ had significant difficulties with tasks requiring close-up vision, and as little as $0.6 \%$ to $1.3 \%$ had significant vision-related difficulty taking part in sport or outdoor activities.

Table S2 shows the change in preoperative to postoperative scores. Both preoperative and postoperative questionnaires were available in approximately $50 \%$ of patients in each category. Preoperatively, patients rated their symptoms with their usual spectacle/contact lens wear. Postoperatively, patients assessed their symptoms without any corrective lenses. The majority of patients had unchanged or increased visual phenomena symptoms, night driving difficulties, and dry eye symptoms. Difficulties with near and distance activities were mostly unchanged, or improved postoperatively. The change in the visual phenomena symptoms or difficulties with night driving, distance and near activities was not statistically significant between age groups (Table S2).

\section{Lens explants}

Table 3 shows the incidence of lens explants in each age category. The difference in number of patients requiring lens explant due to quality of vision issues was not statistically significant $(1.3 \%$ of patients in group A, $0.3 \%$ in group $\mathrm{B}$, $0.9 \%$ in group $\mathrm{C}$, and $0.3 \%$ in group $\mathrm{D}, P=0.57$ ). If the explant rates are calculated on per-eye basis, the percentages are as follows: group A $0.6 \%$, group B $0.2 \%$, group C $0.6 \%$, group D $0.3 \%(P=0.48)$ All explants due to quality of vision were monocular - in all cases, explant of IOL in one 
Table 3 IOL explants

\begin{tabular}{|c|c|c|c|c|}
\hline Age category & $45-49$ years & $50-54$ years & 55-59 years & $60-64$ years \\
\hline IOL explant due to quality of vision issues & 4 eyes $(0.6 \%)$ of & I eye $(0.2 \%)$ of & 2 eyes $(0.3 \%)$ of & I eye $(0.2 \%)$ of \\
\hline (Secondary IOL: monofocal or low near add multifocal IOL) & 4 patients $(1.3 \%)$ & I patient $(0.3 \%)$ & 2 patients $(0.6 \%)$ & I patient $(0.3 \%)$ \\
\hline IOL exchange due to near vision issues & - & - & - & I eye $(0.2 \%)$ of \\
\hline (Secondary IOL: different type of multifocal IOL) & & & & I patient $(0.3 \%)$ \\
\hline IOL exchange for other reasons & - & - & 2 eyes $(0.3 \%)$ of & - \\
\hline (IOL opacification) & & & I patient $(0.3 \%)$ & \\
\hline \multirow[t]{2}{*}{ Total number of IOL explants } & 4 eyes $(0.6 \%)$ of & I eye $(0.2 \%)$ of & 4 eyes $(0.6 \%)$ of & 2 eyes $(0.3 \%)$ of \\
\hline & 4 patients (1.3\%) & I patient $(0.3 \%)$ & 3 patients $(0.9 \%)$ & 2 patients $(0.6 \%)$ \\
\hline
\end{tabular}

Abbreviation: IOL, intraocular lens.

eye (mostly dominant eye) sufficiently alleviated patient's symptoms and explant of multifocal IOL from second eye was not necessary.

Bilateral IOL opacification in group C (Table 2) was observed in a 58-year old female with a Lentis Mplus MF30 LS-313 IOL implant. Apart from a history of sciatica with no regular medications taken for this condition, the patient was reported to be in good health. Right eye IOL opacification was first noted 1 year postoperatively, and left eye 2 years postoperatively. Both IOLs were successfully exchanged to a multifocal IOL of different material, and the UDVA was 20/16 in each eye at the last available appointment.

\section{Postoperative complications}

Table 4 summarizes postoperative complication rates in the four age groups. Of all patients, 76.3\% (976 patients) were available for a minimum of 6 months follow-up and $45.6 \%$ (584 patients) were available for a minimum of 12 months follow-up.

All cases of corneal edema were transient and cleared within the first postoperative week. In all patients with elevated intraocular pressure (IOP), IOP increase was noted in the early postoperative period and returned to preoperative level within the first postoperative month.
All patients with cystoid macular edema (CME) had only one episode. All but one of these cases responded to the treatment with topical steroids/nonsteroidal anti-inflammatory drops and oral acetazolamide. One patient required more prolonged management, as discussed in the following paragraph. The occurrence of CME was not statistically significant between groups.

The case of the prolonged unilateral CME occurred in a 56-year old male who underwent RLE for hyperopia (+2.50 D). Late-onset CME in this patient was first noted 1 year after surgery, reducing CDVA to 20/40. The patient initially responded to treatment and macular thickness significantly reduced, however, one small cyst remained and required management for a further 10 months. This patient also developed a small area of drusen temporal to the macula and was still under investigation at the time of this study. His CDVA was 20/25 at the last available follow-up.

Postoperative iritis was the only complication that was statistically significant in one of the age groups (50-54 years). Most of the patients who developed iritis had a single episode, apart from two patients: a 51-year old male with four episodes up to 6 months postoperatively, and a 56-year old female with two episodes within 3 months postoperatively. All cases of iritis responded to topical steroid treatment.

Table 4 Postoperative complications

\begin{tabular}{|c|c|c|c|c|c|}
\hline & $\begin{array}{l}45-49 \text { years } \\
\text { number of eyes [\%] }\end{array}$ & $\begin{array}{l}50-54 \text { years } \\
\text { number of eyes [\%] }\end{array}$ & $\begin{array}{l}55-59 \text { years } \\
\text { number of eyes [\%] }\end{array}$ & $\begin{array}{l}60-65 \text { years } \\
\text { number of eyes [\%] }\end{array}$ & $P$-value \\
\hline $\begin{array}{l}\text { Mean follow-up } \pm \text { SD } \\
\text { (months) }\end{array}$ & $12.4 \pm 8.4$ & $12.1 \pm 9.0$ & $12.2 \pm 8.3$ & $12.9 \pm 8.5$ & 0.24 \\
\hline Corneal abrasion & $0[0]$ & $4[0.6]$ & $6[0.9]$ & $5[0.8]$ & 0.13 \\
\hline Corneal edema & $4[0.6]$ & $2[0.3]$ & $6[0.9]$ & $7[1.1]$ & 0.38 \\
\hline Elevated intraocular pressure & $3[0.5]$ & $0[0]$ & $\mathrm{I}[0.2]$ & $3[0.5]$ & 0.28 \\
\hline Cystoid macular edema & $3[0.5]$ & $4[0.6]$ & $5[0.8]$ & $3[0.5]$ & 0.86 \\
\hline Iritis & $7[1.1]$ & $19[3]$ & $5[0.8]$ & $9[1.4]$ & 0.008 \\
\hline Retinal detachment & $0[0]$ & $0[0]$ & $0[0]$ & $\mathrm{I}[0.2]$ & 0.39 \\
\hline Endophthalmitis & $0[0]$ & $0[0]$ & $0[0]$ & $0[0]$ & - \\
\hline Posterior capsular opacification & $74[11.6]$ & $62[9.7]$ & $60[9.4]$ & $62[9.7]$ & 0.56 \\
\hline (Underwent nd:YAG capsulotomy) & $(54[8.4])$ & $(49[7.7])$ & $(46[7.2])$ & $(47[7.3])$ & $(0.84)$ \\
\hline
\end{tabular}


There was one case of unilateral RD (left eye) in a 61-year old male with low myopia preoperatively $(-0.75 \mathrm{D}$ sphere with $-0.25 \mathrm{D}$ cylinder) and an axial length of $22.38 \mathrm{~mm}$. Inferior RD occurred 1 year after RLE. The patient had good outcome following RD repair, and his unaided vision in the affected eye eventually returned to 20/16.

The incidence of postoperative PCO and the percentage of patients requiring Nd:YAG capsulotomy was comparable between age groups.

\section{Discussion}

Although more and more surgeons are opting to perform RLE on presbyopes younger than 50 years, ${ }^{12-14}$ to our knowledge, no study has specifically compared the visual, refractive, and quality of life outcomes among different age categories of RLE patients. Younger presbyopes are more active, workingage patients with high visual requirements for near and intermediate vision. They may also have higher quality of distance vision requirements (eg, for night driving, outdoor activities, and sport) than the older patients. Additionally, patients who have not been presbyopic for many years (younger patients) may not fully appreciate the frustration of near vision loss to the same extent as older presbyopes. These older presbyopes have been dependent on near vision correction for a longer time and may be more likely to accept compromise in quality of vision for near vision gain. On the other hand, older patients may have slower visual recovery or an increased risk of complications, either of which could influence postoperative satisfaction.

In terms of clinical outcomes, comparable results were achieved in postoperative sphere, cylinder, and MSE (Table 2) and a similar percentage of eyes achieved emmetropia (Figure 2). Although the difference in preoperative or postoperative CDVA was statistically significant (Table 2 ), the difference was minimal $(0.01 \log$ MAR - less than one letter on Snellen visual acuity chart) and clinically irrelevant. Despite this slight difference in CDVA, all four groups had comparable postoperative uncorrected distance and near visual acuity (Table 2). The difference in loss of two or more lines of CDVA at the 3 months visit was not statistically significant between groups, and in most cases, CDVA returned to $20 / 20$ or better by the final visit.

Quality of vision, night vision phenomena, and loss of contrast sensitivity are the most common reasons for dissatisfaction with multifocal IOLs. ${ }^{15-17}$ To date, no study considered age as a possible factor for increased/decreased satisfaction with multifocal lens implants. The IOL used in the majority of eyes in this study was a non-rotational symmetric refractive multifocal IOL, and its characteristics and visual phenomena specific to this lens design have been previously described. ${ }^{18-22}$ The IOL is known to provide good contrast sensitivity, ${ }^{18-20}$ which is attributable to the presence of only one transition zone between the distance and near vision zone. This, in theory, could reduce the source of scattering and aberrations. ${ }^{18-21}$ Although the near vision with refractive non-rotationally symmetric IOLs is not as good as with some diffractive or hybrid refractive-diffractive IOLs, ${ }^{14,19}$ it provides some depth of focus and a range of near to intermediate vision. ${ }^{18-21}$ Some studies attributed the intermediate vision to the induction of primary coma, ${ }^{18-21}$ which can negatively impact on the quality of image.

Despite the hypothesis that younger patients could be more sensitive to photic phenomena, there was no statistically significant difference in visual phenomena or night driving difficulties reported by patients of different age categories. Most of the patients had little or no difficulties performing tasks requiring close-up vision (Table S1). Between 1.9\% and $3.4 \%$ of patients reported significant difficulty with close-up vision. The difference between groups was again not statistically significant. The percentage of patients having significant difficulty with outdoor activities ranged between $0.6 \%$ and $1.3 \%$, and there was no statistically significant difference between groups.

The incidence of lens explant in this study was very low and comparable between groups (Table 3). In the literature, the most common reasons for IOL explants are lens dislocation, incorrect IOL power, dissatisfaction with image quality (photic phenomena, contrast sensitivity) or IOL opacification ${ }^{17,23,24}$ In this study, the percentage of patients requiring a lens explant due to dissatisfaction with image quality was higher in younger patients $(1.3 \%$ in group A: $45-49$ years, as opposed to $0.6 \%$ or less in remaining categories). However, this difference did not reach statistical significance. We observed one case of bilateral IOL opacification in a 58-year old patient originally implanted with Lentis Mplus LS-313 MF30 lens, which was successfully explanted. No cases of IOL dislocation or IOL tilt occurred in this study, which is mostly due to the IOL design used in most of the patients (plate haptic non-rotational symmetric lens), that is known to have considerably better stability than C-loop haptic lens of the same manufacturer. ${ }^{14,22}$

One of the reasons why RLE is considered controversial in younger presbyopes is the possibility of $\mathrm{RD}$, especially in patients with longer axial lengths. The reported risk of RD following cataract/RLE in highly myopic eyes (in studies with a minimum of 2 years follow-up) is $1.5 \%$ to $8.1 \% .^{6-11}$ 
It is also important to note, that most of the reported cases of $\mathrm{RD}$ were in patients in pre-presbyopic age range (less than 40 years), ${ }^{6-9}$ which is different than our dataset. Although only a small percentage of eyes (less than $3 \%$ in each age category) had preoperative MSE less than $-6.0 \mathrm{D}$, and most of them were treated 2 or more years ago, none of them developed an RD. Interestingly, the only case of RD in this study was observed in a 61-year old patient with an axial length of $22.38 \mathrm{~mm}$, which would normally be considered as a low risk for RD. It is still, however, advisable to carefully counsel and perform a thorough preoperative vitreo-retinal examination in younger patients with incomplete posterior vitreous detachment. All other postoperative complications were comparable between age groups, except for incidence of iritis, which was higher in age category 50-54 years. One would expect higher complication rates in older patients, but this was not confirmed in this study.

\section{Limitations}

One of the limitations of this study was that retrospective data were used for analyses. However, it would prove difficult to conduct a study on such large scale prospectively, and it would likely result in a much lower number of patients in each category. Postoperative follow-up in some patients was not long enough to accurately assess long-term complications, although most of the complications specific to RLE (eg, macular or corneal edema, iritis, raised IOP, endophthalmitis, etc) ${ }^{14}$ tend to occur during early follow-ups. Although the questionnaire used in this study was found effective for reporting subjective outcomes of refractive procedures, ${ }^{14,25,26}$ use of a well-established, validated quality of life instrument could also add to the value of this study. It would also be interesting to compare data samples stratified by axial length, however, in our experience, patient-reported outcomes are mostly dependent on patients' preoperative refractive status, rather than axial length. Therefore, the stratification of data samples in this paper was based on preoperative refraction.

In conclusion, RLE in different age categories resulted in similar clinical outcomes and patient satisfaction rates. As long as all the precautions are taken to minimize the risk of sight-threatening complications, RLE can be safely performed in younger presbyopic patients. Most of the patients in this study had refractive error within the limits of keratorefractive procedures (Figure 1), but elected to undergo RLE to achieve complete spectacle independence. New trends in intraocular surgery, such as introduction of femtosecond lasers to cataract surgery, ${ }^{3,4}$ micro-incision surgery, ${ }^{3,4}$ or use of prophylactic intracameral antibiotics to prevent endopthalmitis, ${ }^{5}$ immensely improved the safety profile of this procedure, hence, phacoemulsification with implantation of IOL is no longer restricted only to patients with cataractous crystalline lens. Preoperative consultation and discussion of the optical side effects remain one of the most important factors in preoperative patient selection.

\section{Disclosure}

Steven C Schallhorn is a chief medical officer for Zeiss, consultant for Acufocus, and a chairman of the medical advisory board for Optical Express. Julie M Schallhorn has been a member of the advisory board for Malinckrodt Pharmaceuticals and received a lecture honorarium payment from Avellino Labs. None of the other authors have a financial or proprietary interest in the products and materials presented in this paper.

\section{References}

1. de Vries NE, Nuijts RM. Multifocal intraocular lenses in cataract surgery: literature review of benefits and side effects. $J$ Cataract Refract Surg. 2013;39(2):268-278.

2. Rosen E, Alió JL, Dick HB, Dell S, Slade S. Efficacy and safety of multifocal intraocular lenses following cataract and refractive lens exchange: Metaanalysis of peer-reviewed publications. $J$ Cataract Refract Surg. 2016;42(2):310-328.

3. Alió JL, Grzybowski A, Romaniuk D. Refractive lens exchange in modern practice: when and when not to do it? Eye Vis (Lond). 2014;1:10.

4. Alio JL, Grzybowski A, El Aswad A, Romaniuk D. Refractive lens exchange. Surv Ophthalmol. 2014;59(6):579-598.

5. Cao H, Zhang L, Li L, Lo S. Risk factors for acute endophthalmitis following cataract surgery: a systematic review and meta-analysis. PLoS One. 2013;8(8):e71731.

6. Barraquer C, Cavelier C, Mejia LF. Incidence of retinal detachment following clear lens extraction in myopic patients. Retrospective analysis. Arch Ophthalmol. 1994;112(3):336-339.

7. Colin J, Robinet A, Cochener B. Retinal detachment after clear lens extraction for high myopia. Ophthalmology. 1999;106(2):2281-2285.

8. Pucci V, Morselli S, Romanelli F, Pignatto S, Scandellari F, Bellucci R. Clear lens phacoemulsification for correction of high myopia. J Cataract Refract Surg. 2001;27(6):896-900.

9. Fernández-Vega L, Alfonso JF, Villacampa T. Clear lens extraction for the correction of high myopia. Ophthalmology. 2003;110(12): 2349-2354.

10. Alio JL, Ruiz-Moreno JM, Shabayek MH, Lugo FL, Abd EL Rahman AM. The risk of retinal detachment in high myopia after small incision coaxial phacoemulsification. Am J Ophthalmol. 2007;144(1):93-98.

11. Neuhann IM, Neuhann TF, Heimann H, Schmickler S, Gerl RH, Foerster MH. Retinal detachment after phacoemulsification in high myopia: analysis of 2356 cases. J Cataract Refract Surg. 2008;34(10): 1644-1657.

12. Westin O, Koskela T, Behndig A. Epidemiology and outcomes in refractive lens exchange surgery. Acta Ophthalmol. 2015;93(1):41-45.

13. Chang JS, Ng JC, Lau SY. Visual outcomes and patient satisfaction after presbyopic lens exchange with a diffractive multifocal intraocular lens. J Refract Surg. 2012;28(7):468-474.

14. Venter JA, Pelouskova M, Collins BM, Schallhorn SC, Hannan SJ. Visual outcomes and patient satisfaction in 9366 eyes using a refractive segmented multifocal intraocular lens. J Cataract Refract Surg. 2013; 39(10):1477-1484. 
15. Woodward MA, Randleman JB, Stulting RD. Dissatisfaction after multifocal intraocular lens implantation. J Cataract Refract Surg. 2009;35:992-997.

16. de Vries NE, Webers CA, Touwslager WR, et al. Dissatisfaction after implantation of multifocal intraocular lenses. J Cataract Refract Surg. 2011;37(5):859-865.

17. Kamiya K, Hayashi K, Shimizu K, Negishi K, Sato M, Bissen-Miyajima H; Survey Working Group of the Japanese Society of Cataract and Refractive Surgery. Multifocal intraocular lens explantation: a case series of 50 eyes. Am J Ophthalmol. 2014;158(2):215-220.

18. Alió JL, Plaza-Puche AB, Piñero DP, Javaloy J, Ayala MJ. Comparative analysis of the clinical outcomes with 2 multifocal intraocular lens models with rotational asymmetry. J Cataract Refract Surg. 2011; 37(9):1605-1614.

19. Alio JL, Plaza-Puche AB, Javaloy J, Ayala MJ, Moreno LJ, Piñero DP. Comparison of a new refractive multifocal intraocular lens with an inferior segmental near add and a diffractive multifocal intraocular lens. Ophthalmology. 2012;119(3):555-563.

20. Alió JL, Piñero DP, Plaza-Puche AB, Chan MJ. Visual outcomes and optical performance of a monofocal intraocular lens and a newgeneration multifocal intraocular lens. J Cataract Refract Surg. 2011; 37(2):241-250.
21. Ramón ML, Piñero DP, Pérez-Cambrodí RJ. Correlation of visual performance with quality of life and intraocular aberrometric profile in patients implanted with rotationally asymmetric multifocal IOLs. $J$ Refract Surg. 2012;28(2):93-99.

22. Alió JL, Plaza-Puche AB, Javaloy J, Ayala MJ, Vega-Estrada A. Clinical and optical intraocular performance of rotationally asymmetric multifocal IOL plate-haptic design versus C-loop haptic design. $J$ Refract Surg. 2013;29(4):252-259.

23. Neuhann I, Fleischer F, Neuhann T. [Reasons for exchange and explantation of intraocular lenses]. Klin Monbl Augenheilkd. 2012; 229(8):794-797. German.

24. Jones JJ, Jones YJ, Jin GJ. Indications and outcomes of intraocular lens exchange during a recent 5-year period. Am J Ophthalmol. 2014;157(1): $154-162$.

25. Brown MC, Schallhorn SC, Hettinger KA, Malady SE. Satisfaction of 13,655 patients with laser vision correction at 1 month after surgery. J Refract Surg. 2009;25(7 Supp1):S642- S646.

26. Schallhorn SC, Venter JA, Hannan SJ, Hettinger KA, Teenan D. Effect of postoperative keratometry on quality of vision in the postoperative period after myopic wavefront-guided laser in situ keratomileusis. J Cataract Refract Surg. 2015;41(12):2715-2723. 


\section{Supplementary materials}

Table SI Postoperative patient-reported outcomes according to age category

\begin{tabular}{|c|c|c|c|c|c|}
\hline Age category & $\begin{array}{l}\text { 45-49 years } \\
(n=320 \text { patients) }\end{array}$ & $\begin{array}{l}50-54 \text { years } \\
\text { ( } n=320 \text { patients) }\end{array}$ & $\begin{array}{l}55-59 \text { years } \\
(\mathrm{n}=320 \text { patients })\end{array}$ & $\begin{array}{l}\text { 60-65 years } \\
(n=320 \text { patients })\end{array}$ & P-value \\
\hline \multicolumn{6}{|c|}{$\begin{array}{l}\text { Thinking about your vision during the last week, how satisfied are you with your vision? } \\
\text { (I= very satisfied, } 2=\text { satisfied, } 3=\text { neither, } 4=\text { dissatisfied, } 5=\text { very dissatisfied) }\end{array}$} \\
\hline Satisfied (score I \& 2) & $87.5 \%$ & $86.9 \%$ & $89.4 \%$ & $89.4 \%$ & \multirow[t]{3}{*}{0.26} \\
\hline Neither (score 3) & $6.9 \%$ & $5.0 \%$ & $6.9 \%$ & $4.7 \%$ & \\
\hline Dissatisfied (score 4 \& 5) & $5.6 \%$ & $8.1 \%$ & $3.8 \%$ & $5.9 \%$ & \\
\hline \multicolumn{6}{|c|}{ Would you recommend vision correction surgery to your friends and relatives? } \\
\hline Yes/no & $91.9 \% / 8.1 \%$ & $93.1 \% / 6.9 \%$ & $94.4 \% / 5.6 \%$ & $92.8 \% / 7.2 \%$ & 0.66 \\
\hline \multicolumn{6}{|c|}{ Has surgery improved your quality of life? } \\
\hline Yes/no & $91.6 \% / 8.4 \%$ & $91.9 \% / 8.1 \%$ & $92.8 \% / 7.2 \%$ & $91.6 \% / 8.4 \%$ & 0.93 \\
\hline \multicolumn{6}{|c|}{ If you had to do it over, would you have vision correction surgery again? } \\
\hline Yes/no & $91.3 \% / 8.8 \%$ & $94.1 \% / 5.9 \%$ & $94.4 \% / 5.6 \%$ & $93.8 \% / 6.3 \%$ & 0.37 \\
\hline
\end{tabular}

Think about your vision during the last week. Please rate the degree of difficulty you experienced with each of the visual symptoms/dry eyes.

(Measured on discrete scale from I= no difficulty to $7=$ severe difficulty).

\section{Starburst}

No or little difficulty

$61.3 \% \quad 60.0 \%$

Moderate difficulty

$32.8 \%$

$56.6 \%$

$62.2 \%$

Significant difficulty

$5.9 \%$

$30.0 \%$

$36.6 \%$

$31.3 \%$

Glare

No or little difficulty

$59.7 \%$

$10.0 \%$

$6.9 \%$

$6.6 \%$

Moderate difficulty

$32.2 \%$

$57.2 \%$

$56.6 \%$

$57.8 \%$

Significant difficulty

$8.1 \%$

$32.5 \%$

$36.3 \%$

$35.0 \%$

Halo

No or little difficulty

$58.8 \%$

$10.3 \%$

$7.2 \%$

$7.2 \%$

Moderate difficulty

$33.1 \%$

$58.4 \%$

$59.1 \%$

$62.5 \%$

$33.1 \% \quad 31.3 \%$

Significant difficulty

$8.1 \%$

$30.9 \%$

$7.8 \%$

$6.3 \%$

Ghosting/double vision

No or little difficulty

$75.9 \%$

$10.6 \%$

$72.5 \%$

$75.6 \%$

$19.7 \% \quad 22.2 \%$

$23.1 \%$

$20.0 \%$

Significant difficulty

$4.4 \%$

$5.3 \%$

$4.4 \%$

$4.4 \%$

Dry eyes

No or little difficulty

$72.8 \% \quad 69.7 \%$

$72.8 \%$

$67.8 \%$

$24.7 \% \quad 26.6 \%$

$25.9 \%$

$29.4 \%$

Significant difficulty

$2.5 \%$

$3.8 \%$

$1.3 \%$

$2.8 \%$

0.26

No or little difficulty (score 0, I), Moderate difficulty (score 3, 4, 5), Significant difficulty (score 6, 7)

Because of your eyesight, how much difficulty do you have with the following activities?

( $I=$ No difficulty, $2=$ A little difficulty, $3=$ Moderate difficulty, $4=A$ lot of difficulty, $5=$ Never try to do this because of my vision, $6=$ Never do this for other reasons)

Driving at night

No or little difficulty

Moderate difficulty

$\begin{array}{ll}73.2 \% & 71.8 \% \\ 15.7 \% & 16.8 \% \\ 11.2 \% & 11.3 \%\end{array}$

$72.5 \%$

$73.9 \%$

$16.8 \% \quad 19.1 \%$

Significant difficulty

$11.3 \%$

$10.7 \%$

$7.0 \%$

Doing work or hobbies that require you to see well up close, such as cooking, fixing things around the house, sewing, using hand tools, or working with a computer

$\begin{array}{lllll}\text { No or little difficulty } & 91.2 \% & 89.3 \% & 90.9 \% & 89.7 \% \\ \text { Moderate difficulty } & 6.0 \% & 7.8 \% & 7.2 \% & 6.9 \% \\ \text { Significant difficulty } & 2.8 \% & 2.8 \% & 1.9 \% & 3.4 \%\end{array}$

$\begin{array}{lllll}\text { Significant difficulty } & 2.8 \% & 2.8 \% & 1.9 \% & 3.4 \%\end{array}$

Taking part in active sports or other outdoor activities that you enjoy (like hiking, swimming, aerobics, team sports, or jogging)

$\begin{array}{lllll}\text { No or little difficulty } & 95.2 \% & 95.1 \% & 96.6 \% & 96.3 \% \\ \text { Moderate difficulty } & 3.5 \% & 4.2 \% & 2.7 \% & 3.0 \% \\ \text { Significant difficulty } & 1.3 \% & 0.6 \% & 0.7 \% & 0.7 \%\end{array}$

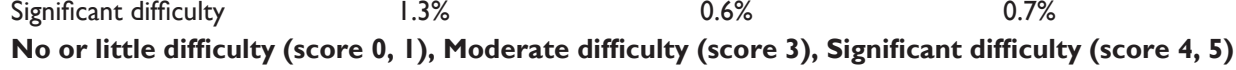


Table S2 Patient-reported outcomes: difference between postoperative and preoperative scores

\begin{tabular}{lllll}
\hline Age category & $\begin{array}{l}45-49 \text { years } \\
(n=146 \text { patients) }\end{array}$ & $\begin{array}{l}50-54 \text { years } \\
(n=153 \text { patients) }\end{array}$ & $\begin{array}{l}55-59 \text { years } \\
(n=162 \text { patients })\end{array}$ & $\begin{array}{l}60-65 \text { years } \\
\text { ( } n=161 \text { patients })\end{array}$ \\
\hline
\end{tabular}

Think about your vision during the last week. Please rate the degree of difficulty you experienced with each of the visual symptoms/dry eyes.

(Measured on discrete scale from $I=$ no difficulty to $7=$ severe difficulty).

$\begin{array}{lllll}\text { Starburst } & & & & \\ \text { Worse } & 20.5 \% & 22.9 \% & 24.1 \% & 19.9 \% \\ \text { Unchanged } & 78.8 \% & 75.8 \% & 75.3 \% & 77.6 \% \\ \text { Better } & 0.7 \% & 1.3 \% & 0.6 \% & 2.5 \% \\ \text { Glare } & & & & \\ \text { Worse } & 19.9 \% & 23.5 \% & 22.8 \% & 18.6 \% \\ \text { Unchanged } & 78.8 \% & 74.5 \% & 76.5 \% & 78.9 \% \\ \text { Better } & 1.4 \% & 2.0 \% & 0.6 \% & 2.5 \% \\ \text { Halo } & & & & 21.7 \% \\ \text { Worse } & 22.6 \% & 22.2 \% & 22.2 \% & 77.6 \% \\ \text { Unchanged } & 75.3 \% & 77.8 \% & 77.2 \% & 0.6 \% \\ \text { Better } & 2.1 \% & 0.0 \% & 0.6 \% & 16.1 \% \\ \text { Ghosting/double vision } & & & & 81.4 \% \\ \text { Worse } & 15.1 \% & 12.4 \% & 11.7 \% & 2.5 \% \\ \text { Unchanged } & 82.9 \% & 87.6 \% & 87 \% & 1.2 \% \\ \text { Better } & 2.1 \% & 0.0 \% & & 16.8 \% \\ \text { Dry eyes } & & & 12.3 \% & 81.4 \% \\ \text { Worse } & 13.0 \% & 14.4 \% & 86.4 \% & 1.9 \% \\ \text { Unchanged } & 84.2 \% & 83.7 \% & 1.2 \% & \\ \text { Better } & 2.7 \% & 2.0 \% & & \end{array}$

\section{$7.6 \%$}

Worse: increase in symptoms by more than 2 scores

Unchanged: preoperative minus postoperative score $0 \pm 2$ scores

Better: decrease in symptoms by more than 2 scores

Because of your eyesight, how much difficulty do you have with the following activities?

( $I=$ No difficulty, 2= A little difficulty, 3= Moderate difficulty, 4= A lot of difficulty, $5=$ Never try to do this because of my vision, $6=$ never do this for other reasons)

\begin{tabular}{|c|c|c|c|c|}
\hline \multicolumn{5}{|c|}{ Driving at night } \\
\hline Worse & $21.7 \%$ & $17 \%$ & $17.8 \%$ & $12.0 \%$ \\
\hline Unchanged & $72.7 \%$ & $76.9 \%$ & $73.0 \%$ & $81.7 \%$ \\
\hline Better & $5.6 \%$ & $6.1 \%$ & $9.2 \%$ & $6.3 \%$ \\
\hline
\end{tabular}

Doing work or hobbies that require you to see well up close, such as cooking, fixing things around the house, sewing, using hand tools, or working with a computer

$\begin{array}{lllll}\text { Worse } & 6.3 \% & 4.6 \% & 1.3 \% & 3.8 \% \\ \text { Unchanged } & 72.7 \% & 69.1 \% & 75 \% & 74.8 \% \\ \text { Better } & 21 \% & 26.3 \% & 23.8 \% & 21.4 \%\end{array}$

Taking part in active sports or other outdoor activities that you enjoy (like hiking, swimming, aerobics, team sports, or jogging)

$\begin{array}{lllll}\text { Worse } & 2.9 \% & 1.3 \% & 0.0 \% & 1.4 \% \\ \text { Unchanged } & 79.7 \% & 80.5 \% & 74.3 \% & 79.7 \% \\ \text { Better } & 17.4 \% & 18.1 \% & 25.7 \% & 18.9 \%\end{array}$

Worse: increase in symptoms by more than I score

Unchanged: preoperative minus postoperative score $0 \pm 1$ score

Better: decrease in symptoms by more than I score

Notes: Patients rated their preoperative symptoms/difficulties with best spectacle/contact lens correction; postoperative symptoms were rated without any spectacle/ contact lens correction.

Clinical Ophthalmology

\section{Publish your work in this journal}

Clinical Ophthalmology is an international, peer-reviewed journal covering all subspecialties within ophthalmology. Key topics include: Optometry; Visual science; Pharmacology and drug therapy in eye diseases; Basic Sciences; Primary and Secondary eye care; Patient Safety and Quality of Care Improvements. This journal is indexed on

Submit your manuscript here: http://www.dovepress.com/clinical-ophthalmology-journal

\section{Dovepress}

PubMed Central and CAS, and is the official journal of The Society of Clinical Ophthalmology (SCO). The manuscript management system is completely online and includes a very quick and fair peer-review system, which is all easy to use. Visit http://www.dovepress.com/ testimonials.php to read real quotes from published authors. 